\title{
Description and characterization of the Amazonian entomopathogenic bacterium Photorhabdus luminescens MN7
}

Fernando L. Kamitani ${ }^{1, \# a}$, Daniela P. Almenara ${ }^{1}$, Carolina Rossi ${ }^{1}$, Maira R. Camargo Neves ${ }^{1}$, Lissandra M. A. Müller ${ }^{1}$, Arthur Gruber ${ }^{1}$, João M. P. Alves ${ }^{1}$, Lydia F. Yamaguchi $^{2}$, Nídia C. Yoshida ${ }^{2, \# b}$, Massuo J. Kato ${ }^{2}$, Carlos E. Winter ${ }^{*}$

${ }^{1}$ Department of Parasitology, Institute of Biomedical Sciences, University of São Paulo, São Paulo, São Paulo, Brazil

${ }^{2}$ Department of Fundamental Chemistry, Institute of Chemistry, University of São Paulo, São Paulo, São Paulo, Brazil

${ }^{\# a}$ Current address: Parasitology Laboratory, Instituto Butantan, São Paulo, São Paulo, Brazil

${ }^{\#}$ Current address: Institute of Chemistry, Federal University of Mato Grosso do Sul, Campo Grande, Mato Grosso do Sul, Brazil

*Corresponding author

E-mail: cewinter@icb.usp.br (CEW) 


\section{Abstract}

Many isolates of the genus Photorhabdus have been reported around the world. Here

we describe the first Brazilian Photorhabdus isolate, found in association with the entomopathogenic nematode Heterorhabditis baujardi LPP7, from the Amazonian forest in Monte Negro (RO, Brazil). The new isolate can be grouped with the $\mathrm{Hb}-\mathrm{Hm}$ clade of $P$. luminescens subsp. luminescens, close to the new subspecies $P$. luminescens subsp. sonorensis. P. luminescens MN7 has several characteristics expected of variant form I cells, such as the presence of intracellular crystals, secretion of hydrolytic enzymes (lipases and proteases) and bioluminescence. Although H. baujardi LPP7 is not prolific when compared to H. bacteriophora HP88, P. luminescens MN7 is clearly pathogenic and probably secretes the same toxins as $P$. luminescens subsp. luminescens W14, when fed to larvae of the greater wax moth Galleria mellonella. This behavior is different from what is found in Photorhabdus luminescens subsp. laumondii HP88, which was used as a control in our experiments, and P. l. subsp. laumondii TT01. Besides the toxin secretion, $P$. luminescens MN7 secretes proteolytic polypeptides that have molecular masses different from those found in P. l. subsp. laumondii TT01.

40 Finally, the crude extract from spent culture medium was shown to contain 3,5dihydroxy-4-isopropyl-cis-stilbene and 1,3,8-trihydroxy-9,10-anthraquinone as the major compounds, similarly to other Photorhabdus luminescens strains.

Keywords: Photorhabdus, Heterorhabditis, protease, secreted toxin, stilbene, 


\title{
Introduction
}

\author{
Bacteria belonging to genus Photorhabdus are symbiotically associated with
} entomopathogenic nematodes of the genus Heterorhabditis [1, 2]. These Gram-negative $\gamma$-proteobacteria undergo a complex life cycle [3], characterized as a multipartite mutualism [4], that results in the death of the infected insect. Release of bacterial secondary metabolites inside the insect cadaver maintains the milieu free of competing bacteria [5]. Some of the secondary metabolites produced by Photorhabdus [6] could be used for pest control [7, 8] or drug development [9]. The genus Photorhabdus comprises three species (P. luminescens, $P$. temperata and $P$. asymbiotica) [10]. $P$. luminescens is subdivided into four subspecies: P. luminescens subsp. akhurstii, $P$. luminescens subsp. laumondii, P. luminescens subsp. luminescens [10], and the recently described P. luminescens subsp. sonorensis, isolated from $H$. sonorensis [11]. Extensive phylogenetic analyses $[12,13]$ have demonstrated the need for a multigene approach to establish a consistent taxonomy of the genus Photorhabdus.

When grown in solid media, Photorhabdus luminescens presents two phenotypic variant forms. Variant form I cells are those isolated from the infected insects and present active biosynthesis of secondary metabolites [14]. Variant form II cells are observed in some strains after successive in vitro plating and have a more restricted metabolism [15]. They differ from variant form I cells in colony morphology, cell size, dye uptake conditions, virulence, and infection properties [16]. Another natural variation occurs when the bacteria change hosts during the life cycle. In fact, the bacterial cells can exist in two alternate forms: a pathogenic one $(\mathrm{P})$ within the insect and a smaller one (M) inside the nematode, associated with the expression of the mad operon that codes for the maternal adhesion fimbriae [17].

Several toxins have been characterized in Photorhabdus [18]. Some, like the Mcf toxin, kill by inducing apoptosis [19]; others, like the Tc toxins, alter the cytoskeleton of the hosts cells [20]. The toxins produced by Photorhabdus spp. vary even among different subspecies. Subspecies of the clade $\mathrm{Hb} / \mathrm{Hm}$ are characterized by secretion of toxins of the Tcd complex into the culture medium, whereas subspecies of other clades, like P. luminescens subsp. laumondii TT01, do not show this phenotype [21]. Such a phenotype is related to the presence of a putative lipase activity [21] and confers oral toxicity to the supernatant of a culture of $P$. luminescens classified in the $\mathrm{Hb} / \mathrm{Hm}$ clade. 
Another important aspect of Photorhabdus physiology is the biosynthesis and secretion of hydrolytic enzymes. Two hydrolases are important members of the toxin arsenal of Photorhabdus and are responsible for the pathogenic effect on insects: the PrtA protease [22] and the toxin-associated lipase Pdl1 [21]. PrtA is a metalloenzyme belonging to the subfamily of the serralysins (subfamily M10B) [22]. PrtA hydrolyzes proteins involved in the insect's innate immune response [23].

A central aspect of the Photorhabdus life cycle is light emission, associated with the luxCDABE operon, and used as the primary taxonomic feature to distinguish this genus from the sister entomopathogenic genus, Xenorhabdus spp. [24]. The amount of light produced varies with the isolate: some emit strong luminescence; others emit light of very faint intensity $[25,26]$. An important aspect of the luxCDABE operon is the probable quorum sensing control of its expression. Quorum sensing is not mediated by AHL (acyl homoserine lactones) in Photorhabdus, but a pyrone is involved in the interaction with some of the LuxR-type proteins coded in several of its genes [27].

Although strains of Photorhabdus luminescens have been isolated and characterized from several geographic locations, none had been completely characterized in Brazil so far. In this work, we describe and characterize the first Brazilian Photorhabdus luminescens isolate, associated with Heterorhabditis baujardi LPP7 [28]. Strain MN7 of P. luminescens, isolated from this Brazilian nematode, shows a low bioluminescence activity and can secrete an insecticidal toxin similar to that found in P. luminescens W14. Molecular phylogeny analyses, using structural and ribosomal genes of MN7, place this strain in the branch of $P$. luminescens $\mathrm{Hb}$ and $\mathrm{Hm}$.

\section{Materials and methods}

\section{Bacteria isolation, growth and maintenance}

For initial isolation of bacteria, infective juveniles (IJ) of Heterorhabditis baujardi strain LPP7 [28] were cleaned with 0.5\% hypochlorite solution for $8 \mathrm{~min}$ [29] and seeded over Lysogeny Broth (LB) agar plates without glucose [30]. The plates were incubated at $28^{\circ} \mathrm{C}$ until bacterial colonies could be detected. Photorhabdus colonies were identified by sequencing PCR-amplified 16S rDNA fragments (see below) and by checking for bioluminescence. The isolated strain was maintained in LB-agar plates 
containing $0.1 \%$ sodium pyruvate to increase cell viability [31], as suggested by Blackburn et al. [32]. Heterorhabditis bacteriophora HP88 was used as a source of $P$. luminescens subsp. laumondii strain HP88, isolated as described for H. baujardi. Some experiments were done by growing $H$. baujardi LPP7 and P. luminescens MN7 in nutrient agar $(0.5 \%$ meat peptone, $0.3 \%$ meat extract, $1.2 \%$ agar) containing $1 \%$ corn oil and $0.5 \%$ cholesterol.

\section{DNA extraction and sequencing}

An overnight culture of $P$. luminescens MN7 was centrifuged and washed with PBS (16 $\left.\mathrm{mM} \mathrm{Na}_{2} \mathrm{HPO}_{4}, 4 \mathrm{mM} \mathrm{NaH}_{2} \mathrm{PO}_{4}, 150 \mathrm{mM} \mathrm{NaCl}\right)$. The pellet was resuspended in TE (10 mM Tris-HCl pH 8.0, $1 \mathrm{mM}$ EDTA) and DNA was extracted using the QIAGEN Gentra Puregene Yeast/Bact. Kit. DNA sequencing was performed either by the dideoxi method [33] or by pyrosequencing [34]. Pyrosequencing was done at Macrogen (Seoul, South Korea) in a 454 sequencer (Roche Diagnostics Corporation). Complete SSU rDNA sequence was obtained from a DNA fragment generated by PCR using primers PL_SSU_f (GAAGAGTTTGATCATGGCTC) and PL_SSU_r (AAGGAGGTGATCCAACCGCA). The oligonucleotides utilized for sequencing the whole fragment are shown in S1 Table. Six genes of P. luminescens MN7 were completely sequenced in this study and their GenBank/EMBL accession are as follows: KY581573 (dnaN), KY581574 (glnA), KY581575 (gltX), KY581576 (gyrB), KY581577 (recA) and KY581578 (SSU rDNA).

\section{Phylogenetic analysis}

Phylogenetic analyses were performed using concatenated sequences from either five different genes, as previously described [12] and subsequently modified [11] (see S2 Table), or three different genes as formerly described [13] (SSU rDNA, $g \ln A$ and gyrB) (see S3 Table). DNA sequences were aligned using Clustal X v. 2.0.12 [35] and the resulting alignments were edited using Jalview v. 2.6.1 [36]. The alignments obtained for each gene were used to choose the best-fitting evolutionary models using the Bayesian Information Criterion (BIC) [37] implemented in jModelTest v. 2.1.4 [37, 38]. Concatenation of the aligned genes was done with FASconCAT [39]. Mixed model Bayesian analyses were performed with MrBayes v. 3.1.2 [40] on the concatenated 
147

sequences. Posterior probabilities were calculated using at least 1,000,000 generations sampled every 100 generations, four chains of MCMC, and a burn-in of $25 \%$ of all generated trees. Maximum likelihood analysis on the same concatenated datasets were performed with RAxML ver. 7.0.3 [41] using the GTR+gamma+I model and generating 5000 bootstrap pseudoreplicates. Trees were drawn with FigTree (v. 1.4.0; http://ree.bio.ed.ac.uk/software/figtree/). Partial alignments of SSU rRNA sequences were further examined with Pontos, ver. 3.0 (J.M.P Alves, unpublished, available at https://sourceforge.net/projects/pontos/).

\section{Bacteriological assays and antibiotic analysis}

Bacterial cultures were grown until the stationary phase and then inoculated into MILi [42] or EPM [43] media from the kit EPM-MILi (Newprov, São Paulo, Brazil). This kit allowed the simultaneous assay of glucose fermentation; $\mathrm{H}_{2} \mathrm{~S}$ production (desulfhydrase activity); $\mathrm{CO}_{2}$ production from glucose fermentation; L-tryptophan deaminase activity; urease activity; motility; tryptophan hydrolase activity; and lysine decarboxilase activity. After an overnight incubation at $28^{\circ} \mathrm{C}$, results were read as recommended by the manufacturer. Antibiotic resistance was tested using antibioticcontaining paper discs (Multidisk kits Laborclin, São Paulo, Brazil, Cat. No. 640664 and 640665).

\section{Bioluminescence detection}

LB plates containing Photorhabdus spp. colonies or individual Galleria mellonella larvae infected with Heterorhabditis spp. were observed in a Bio-Rad Molecular Imager ${ }^{\circledR}$ ChemiDoc ${ }^{\mathrm{TM}}$ XRS + System and analyzed with Bio-Rad Image Lab software, version 4.0 build 16 (Bio-Rad Laboratories).

\section{Protease electrophoretic assay}

Proteins were dissolved in sample buffer [62.5 mM Tris-HCl, $\mathrm{pH} 6.8$ containing $12.6 \%(\mathrm{v} / \mathrm{v})$ glycerol, $0.015 \%(\mathrm{w} / \mathrm{v})$ bromophenol blue, $1 \%(\mathrm{w} / \mathrm{v})$ SDS and 2.5\% 2mercaptoethanol], and the samples were loaded onto the gels with no prior heating. The SDS-PAGE running gel contained $500 \mu \mathrm{g} / \mathrm{mL}$ of bacto-gelatin (Difco). The 
181

182

183

184

185

186

187

188

189

190

191

192

193

194

195

196

197

198

199

200

201

202

203

204

205

206

207

208

209

210

211

212

213

214

electrophoretic run was done at $4^{\circ} \mathrm{C}$ using constant current $(5 \mathrm{~mA})$ in a Hoeffer mini-gel system. After electrophoresis, the gel was incubated at $4^{\circ} \mathrm{C}$ for $30 \mathrm{~min}$ in equilibration buffer [100 mM Tris-HCl pH 8.0 and 2.5\% (v/v) Triton X-100]. This step was repeated once and followed by incubation in the same buffer without detergent. After the last incubation step, the gel was maintained for 18 hours in $100 \mathrm{mM}$ Tris-HCl pH 8.0 at $4^{\circ} \mathrm{C}$. After incubation, the gel was fixed with $10 \%(\mathrm{w} / \mathrm{v})$ trichloroacetic acid, washed with water and stained with Coomassie Blue R-350 [44].

\section{Lipase assay}

Lipase production was detected as described [45] in peptone agar plates [1.5\% (w/v) bacto-agar, $0.1 \%$ (w/v) bacto-peptone, $\left.85 \mathrm{mM} \mathrm{NaCl}, 0.78 \mathrm{mM} \mathrm{CaCl}_{2}, \mathrm{pH} 7.4\right]$ containing $0.5 \%(\mathrm{v} / \mathrm{v})$ Tween 20 or Tween 80 . Lipase production was observed as a white precipitate around the bacterial colonies after incubation at $28^{\circ} \mathrm{C}$ for $72 \mathrm{~h}$.

\section{DIC microscopy}

Samples containing $10 \mu \mathrm{L}$ of bacterial suspension, taken directly from the culture, were observed in a Zeiss Axiophot photomicroscope and photographed with a CoolSNAP HQ2 CCD Camera (Photometrics, Tucson AZ, USA) using Metamorph NX (Microscopy Automation and Image Analysis Software version 7.7.7, Molecular Devices). Bacterial cell size was determined using a $0.01 \mathrm{~mm}$ precision stage micrometer (Bausch \& Lomb, Rochester NY, USA).

\section{Transmission electron microscopy}

Bacterial cultures of $P$. luminescens MN7 were centrifuged at 4,500 $\mathrm{g}$ for $10 \mathrm{~min}$ and resuspended in PBS. A bacterial suspension at a concentration of $10^{6}$ cells $/ \mathrm{mL}$ was used for the drop application method of negative staining with phosphotungstic acid using carbon-coated 300-mesh copper grids [46] and observed in a JEOL 1010 transmission electron microscope.

\section{Secondary metabolite extraction and analysis}


Bacteria were grown in Casein Hydrolysate medium (Oxoid, UK) with 0.1\% proline, for $72 \mathrm{~h}$ at $28^{\circ} \mathrm{C}$. Cells were pelleted by centrifugation at $4,000 \mathrm{~g}$ for $10 \mathrm{~min}$ at $4^{\circ} \mathrm{C}$. Culture medium free of bacterial cells was extracted with ethyl acetate. Identification and purification of the metabolites were performed through TLC (thin layer chromatography) or HPLC-MS (High performance liquid chromatography - Mass spectrometry). Experimental procedures are detailed in the Supplementary Methods (S5 File).

P. luminescens MN7, P. luminescens HP88, P. luminescens TT01 were grown in LB medium ( $1 \%$ tryptone, $0.5 \%$ yeast extract, $170 \mathrm{mM} \mathrm{NaCl}, \mathrm{pH} 7.0)$ at $28^{\circ} \mathrm{C}$ for $72 \mathrm{~h}$ at $180 \mathrm{rpm}$ (200 mL liquid culture in a $1000 \mathrm{~mL}$ Erlenmeyer). Cells were collected by centrifugation at 5,400 $\mathrm{g}$ for $15 \mathrm{~min}$, washed once with PBS and resuspended in PBS using $1 / 15$ of the initial culture volume. The supernatant of this centrifugation, hereafter named spent medium, was kept at $4^{\circ} \mathrm{C}$ and used within $2 \mathrm{~h}$ of collecting. Eleven grams of pollen, used as a component of food for G. mellonella larvae [47], were mixed with $3.0 \mathrm{~mL}$ of spent medium (with or without heating at $70^{\circ} \mathrm{C}$ for $10 \mathrm{~min}$ ) or PBSresuspended bacterial cells. Control groups were fed with pollen mixed with PBS or sterile LB medium instead of cells or spent medium respectively. Assays were performed by growing ten Galleria mellonella larvae at $28^{\circ} \mathrm{C}$ in the different pollen mixtures plus $3.6 \mathrm{~g}$ of bee wax in a Petri dish. Every other day the larvae were individually weighed and larval growth was expressed as relative weight gain (RWG) [21], calculated as follows: $R W G=1+[($ sample mean - control mean $) /$ control mean $]$. Growth of the larvae was followed for 8 days in the dark. Initial mean weight of the larvae was $20 \pm 1 \mathrm{mg}$ (mean \pm SEM) (see S4 Fig). Each assay was performed with three biological replicates. Statistical analysis was carried out using Prism 5.0 (GraphPad

242 Software Inc.) using an unpaired, two tailed t-test $(\mathrm{p}<0,05)$. 
Cells of $P$. luminescens MN7 grown either in LB-pyruvate or nutrient agar show the same morphology and size (Figs 1a and 1b). These cells present prominent inclusions that probably correspond to crystals of polypeptides CipA and CipB, whose function is unknown but are necessary for the growth of the nematode [48]. When $P$. luminescens MN7 is cultivated in LB-pyruvate, starting from 24h after the inoculum, crystals are easily detected within the cells by differential interference contrast (DIC) microscopy. Negative staining and electron microscopy of LB-pyruvate grown bacteria clearly show the presence of peritrichous flagella (Fig 1c) suggesting that MN7 is motile as has been observed in other Photorhabdus isolates [1].

Figure 1. Microscopic analysis of $\boldsymbol{P}$. luminescens MN7. Light microscopy (a and b) with differential interference contrast of $P$. luminescens strain MN7 and transmission electron microscopy (c) with negative staining, grown for (a) seven days with $H$. baujardi LPP7 in nutrient agar containing corn oil and cholesterol; (b) four days in LB pyruvate, as described in Materials and Methods; and (c) $48 \mathrm{~h}$ in LB pyruvate.

Arrowheads show the peritrichous flagella.

Molecular Taxonomy

As a first approach to the characterization of the isolate MN7, we sequenced the SSU (16S) rRNA gene. This sequence was subsequently confirmed by whole-genome sequencing of $P$. luminescens MN7 (data not shown). Using the putative 2D structure of MN7 SSU rRNA (S6 Fig), we analyzed the more variable regions in the alignment of SSU rRNA sequences, obtained from several isolates of Photorhabdus and belonging to different species. S7 Fig shows the partial SSU rDNA alignment and demonstrates that substitutions can occur in any region of the molecule.

To classify the isolate MN7, we used alignments of concatenated gene sequences and Maximum Likelihood and Bayesian Inference phylogenetic approaches. Two sets of genes were used for this analysis. The first set, containing five DNA sequences, is the same one described previously [11] (S2 Table) and includes DNA sequences from 40 organisms. Another set, based on the group of genes used by Peat et al. [13], comprised three concatenated DNA sequences from 65 organisms, including other $\gamma$-proteobacteria used as outgroups (S3 Table). Complete results are shown in S8-S11 Figs The tree constructed with five concatenated gene sequences puts MN7 in a basal position of the $\mathrm{Hb}-\mathrm{Hm}$ clade (that includes strains MX4A, Caborca, and CH35) (Fig 2a-b). On the 
bioRxiv preprint doi: https://doi org/10.1101/328377; this version posted May 22,2018 . The copyright holder for this preprint (which was not certified by peer review) is the author/funder, who has granted bioRxiv a license to display the preprint in perpetuity. It is made available under aCC-BY 4.0 International license.

276 other hand, trees constructed with only three concatenated gene sequences (Fig 2c-d)

277 group strain MN7 with strains $\mathrm{Hb}$ and $\mathrm{Hm}$. Both sets of trees clearly show that MN7

278 does not group with strains MX4A, Caborca, and CH35. The five concatenated gene

279 sequences used to construct the trees shown in Figures $2 \mathrm{a}$ and $\mathrm{b}$ were recently used to

280 describe $P$. luminescens sonorensis [11]. The $\mathrm{Hb}-\mathrm{Hm}$ clade is still sparsely populated

281 with well characterized isolates for us to assign a subspecies classification for $P$.

282 luminescens MN7.

\section{Fig 2. Phylogenetic analysis of strains belonging to the $\mathbf{H b}-\mathbf{H m}$ clade of}

Photorhabdus luminescens. Trees were constructed using concatenated sequences of genes SSU rDNA, gyrB, recA, gltX and $\operatorname{dna\mathrm {N}}(\mathrm{a}$ and b) or genes SSU rDNA, recA and $g y r \mathrm{~B}$ (c and d), using either Maximum Likelihood (a and c) or Bayesian Inference (b and d) approaches. The scale bars indicate changes per site. The figure shows only the clade of interest cut out from complete trees (see S8-S11 Figs). 
Variant forms I and II of P. luminescens strains can be distinguished from each

Fig 3. Secreted hydrolases of $\boldsymbol{P}$. luminescens. (a) Lipase activity secreted by colonies of $P$. luminescens MN7 and TT01 in media containing Tween 20 or Tween 80. Colonies were photographed over white or black backgrounds. (b) Secreted protease activity detected by SDS-PAGE in the culture supernatant of $P$. luminescens TT01 and MN7. Ten microliters of culture medium were collected at different times after an initial inoculum of $50 \mu \mathrm{L}$ of a stationary phase culture into $50 \mathrm{~mL}$ of LB. Culture proceeded at $28^{\circ} \mathrm{C}$ and $150 \mathrm{rpm}$ for $72 \mathrm{~h}$. Cell free medium samples were fractionated in SDS-PAGE $(\mathrm{T}=10 \%)$ containing $0.5 \%(\mathrm{w} / \mathrm{v})$ gelatin. After electrophoresis, the gel was stained with Coomassie Blue. Samples: MN7 (M) and TT01 (T).

287 other by some physiological characteristics such as colony characteristics,

288 ultrastructural elements, cytological properties, enzymatic activities and secondary metabolite production [1]. We could detect the activity of two different secreted enzymes in P. luminescens MN7: a lipase, using a direct method on LB-agar (Fig 3a), and a protease, using an electrophoretic method (Fig 3b). These findings confirm that our isolate contains mainly variant form I cells. Also, the lipase activity (measured by the diameter of the precipitation zone around the bacterial colony) of $P$. luminescens MN7 is more intense than TT01 colonies (Fig 3a). After 18h of bacterial growth, protease activity was more intense in MN7 than in TT01 culture supernatants (Fig 3b). From 6 to 12 h, only a faint protease activity could be found in TT01 cultures and, after this period, bands of prtA and prtS became more prominent in MN7 cultures. The putative prtA bands of TT01 and MN7 show almost the same molecular mass $(\mathrm{Mr}=48$ $50 \mathrm{kDa})$, whereas the prtS band of MN7 $(\mathrm{Mr}=35-38 \mathrm{kDa})$ is smaller than the one detected in TT01 $(\mathrm{Mr}=42 \mathrm{kDa})$. Zymogram profile of MN7 did not show any alteration until $96 \mathrm{~h}$ of culture. Conversely, TT01 cultures showed two small bands around $30 \mathrm{kDa}$ after $48 \mathrm{~h}$ of culture. These bands can be ascribed to either degradation of the main proteases (prtA and prtS) or to intracellular enzymatic activities leaking from lysed cells. 
P. luminescens $\mathrm{MN7}$ is unable to grow in minimal medium with $\mathrm{NH}_{4} \mathrm{Cl}$ as the only nitrogen source but is capable of glucose fermentation and $\mathrm{CO}_{2}$ production. MN7 cells are motile and do not produce lysine decarboxylase, tryptophanase and desulfhydrase. Tryptophan hydrolase and urease activities were not detected in the biochemical tests (Table 1). MN7 is unable to grow in LB-agar at temperatures higher than $32^{\circ} \mathrm{C}$.

Table 1. Phenotypic characters of Photorhabdus luminescens MN7.

\begin{tabular}{lc}
\hline Characteristic & Phenotype \\
\hline Glucose fermentation & $+^{\mathrm{a}}$ \\
$\mathrm{H}_{2} \mathrm{~S}$ production (desulfhydrase activity) & - \\
Gas production from glucose fermentation & + \\
L-Trp deaminase & - \\
Urease & - \\
Trp-hydrolase & - \\
Lys-decarboxylase & - \\
Motility & + \\
\hline
\end{tabular}

Results obtained using the EPM-MILi kit as described in Material and methods. a +: positive, - : negative.

\section{Antibiotic resistance}

We tested the MN7 isolate against a set of multiple antibiotics using a classical agar-diffusion assay (Fig 4). MN7 showed resistance to ampicillin (10 $\mu \mathrm{g} / \mathrm{disc})$, partial resistance to cefalotin (30 $\mu \mathrm{g} / \mathrm{disc})$ and gentamicin $(10 \mu \mathrm{g} / \mathrm{disc})$ and susceptibility to the other antibiotics tested.

Fig 4. Antibiotic agar-diffusion assay of $\boldsymbol{P}$. luminescens MN7. A sample of stationary phase liquid culture of $P$. luminescens MN7 was spread over a plate of LB agar-pyruvate and different antibiotic-impregnated paper discs were applied onto the medium. Results were read after incubation at $28^{\circ} \mathrm{C}$ for $48 \mathrm{~h}$.

\section{Bioluminescence}

Light emission by Photorhabdus spp. can be detected either in insect corpses or in the growth medium, and may vary according to the species. We compared the light emission of isolated bacteria and of G. mellonella larvae infected either with $H$. baujardi LPP7 (containing MN7 cells as symbionts) or H. bacteriophora HP88 (containing P. luminescens subsp. laumondii cells as symbionts) (Fig 5). Light emission 
of LPP7-infected G. mellonella larvae is weaker (Fig 5c) than larvae infected with HP88

329 (Fig 5d). When LB-agar plated with the isolated bacteria were analyzed in the same way we could observe that MN7 colonies (Fig 5g) emit much less light than TT01 cells (Fig $5 h)$.

Fig 5. Bioluminescence detection in Heterorhabditis spp. infected G. mellonella larvae and colonies of $\boldsymbol{P}$. luminescens. Larvae were infected with IJs of $H$. baujardi LPP7 (a and c) or H. bacteriophora HP88 (b and d). $96 \mathrm{~h}$ post-infection, the larvae were observed under visible light ( $\mathrm{a}$ and $\mathrm{b}$ ) or exposed for $52.5 \mathrm{~s}$ in the dark to detect light emission (c and d). P. luminescens MN7 (e and g) and P. luminescens TT01 (f and $\mathrm{h}$ ) were cultivated in LB agar-pyruvate medium for $72 \mathrm{~h}$ at $28^{\circ} \mathrm{C}$. Results were recorded using visible light (e and f) or a 40-second exposure in the dark to detect light emission ( $g$ and $h$ ).

\section{Secreted insect toxins}

To determine the toxicity of MN7's culture supernatant, we have maintained

336 Galleria mellonella larvae in growth medium in the presence or absence of supernatant 337 of cultures of $P$. luminescens HP88 or P. luminescens MN7. The initial mean weight of 338 the larvae was $20 \pm 1 \mathrm{mg}$ (mean \pm SEM) (see S4 Fig) and the experiments followed the growth of the larvae for eight days, at $28^{\circ} \mathrm{C}$ in the dark. RWG values were determined as described. We observed no detectable toxic activity in HP88 (P. luminescens laumondii) supernatant (spent medium). On the other hand, the MN7 culture supernatant (spent medium) (as well as HP88 and MN7 cells) contained toxin activity

343 that significantly decreased larval weight gain after eight days. (Fig 6a). The toxin is 344 heat-sensitive, since heating the $\mathrm{MN} 7$ spent medium at $70^{\circ} \mathrm{C}$ for $10 \mathrm{~min}$ was enough to abolish its effect on the RWG (Fig 6a). The toxin present in the spent medium of MN7 or cells of HP88 has a gradual effect on the decrease of the RWG of G. mellonella larvae as observed in the time curve (Fig 6b). 
Fig 6. Toxin secretion assay of P. luminescens MN7 and HP88 using Galleria mellonella larvae as hosts. (a) Relative weight gain of larvae maintained for eight days under different diets. Differences were analyzed by unpaired, two tailed t-test at $\mathrm{p}<0.05$ (b) Time curve of RWG. Error bars correspond to SEM (standard error of the mean). Spent Medium: cell-free medium after bacterial growth for $72 \mathrm{~h} ; \Delta$ Medium: Spent Medium heated at $70{ }^{\circ} \mathrm{C}$ for $10 \mathrm{~min}$. Controls of spent medium and $\Delta$ medium group were larvae fed on sterile LB. Control of Cells (larvae fed on bacterial cells suspended in PBS) were larvae fed on sterile PBS.

Antibiotic activity

350

Photorhabdus produces and secretes many secondary metabolites with antibiotic

properties. The secondary metabolites extracted from the culture medium of $P$.

luminescens MN7 were analyzed by high-performance liquid chromatography coupled with high resolution electrospray ionization mass spectrometry (HPLC-HRESIMS).

Several peaks could be detected in the crude extract from medium where bacteria were grown for $72 \mathrm{~h}$ (Fig 7a). Peaks 4 and 5 of the HPLC UV profile corresponded respectively to 3,5-dihydroxy-4-isopropyl-cis-stilbene and 1,3,8-trihydroxy-9,10anthraquinone, metabolites that have already been described from other Photorhabdus luminescens strains (see S12 Table and S13 Fig). A fraction containing the 3,5dihydroxy-4-isopropyl-cis-stilbene, according to high resolution electrospray mass spectrum ([M-H]- 253.1234) and ${ }^{1} \mathrm{H}$ NMR [49], was purified by preparative TLC (see Supplementary Material and Methods, S5 File) (S14 Fig) and assayed for antibiotic activity. When applied to a Staphylococcus aureus culture in LB-agar, the purified stilbene presented a growth inhibition zone (Fig 7b), showing antibiotic activity against gram-positive bacteria. 
Fig 7. Analysis of secondary metabolites produced by $P$. luminescens MN7. (a) HPLC-UV profile of secondary metabolites, as described in Supplementary Material and Methods (S5 File). Samples derived from the numbered peaks were further analyzed by MS and their putative compositions are shown in S12 Table. Peaks 4 and 5, corresponding to stilbene and anthraquinone, have retention times of 27.4 and $31.0 \mathrm{~min}$ respectively (see S13 Fig). (b) Growth inhibition of Staphylococcus aureus by preparative TLC-purified stilbene. Filter paper discs impregnated with 10 or $20 \mu \mathrm{g}$ of purified stilbene (S) were applied over a continuous lawn of Staphylococcus aureus culture in LB agar. Control discs (C) consisted of filter paper discs impregnated with

\section{Discussion}

The results presented here show that the MN7 strain is closely related to a recently described subspecies which has been classified as $P$. luminescens subsp. sonorensis, symbiotic partner to Heterorhabditis sonorensis [11]. Heterorhabditis sonorensis is a natural pathogen of the cicada Diceroprocta ornea, a pest of asparagus cultures in the Sonoran Desert of Mexico [50]. MN7 has a neotropical nematode partner, Heterorhabditis baujardi, found in the Amazonian forest with no known exclusive insect target [28]. Seven strains of H. baujardi were originally isolated from the Amazonian Forest at Rondônia state, Brazil [28]. From those strains, only LPP7 showed the production of significant number of infective juveniles (IJ) in G. mellonella assays. Nevertheless, when compared to H. bacteriophora HP88, H. baujardi LPP7 gives rise to smaller amounts of IJ than H. bacteriophora HP88 (not shown).

The alignment of Photorhabdus SSU rRNA sequences (S7 Fig) shows that some of the stems are more variable than expected for the maintenance of the secondary structure (see loop H441 and surrounding stems, Figs S1 and S2). On the other hand, loop H61, which is highly variable in the SSU rRNA of enterobacteria (S6 Fig) is highly conserved among the Photorhabdus sequences analyzed (S7 Fig). These observations suggest that the evolution of Photorhabdus SSU rRNAs is not subjected to the same structural constraints of other enterobacteria.

If we took only the variable regions chosen by us (Figs S1 and S2), we would group organisms that have not been clustered by other approaches $[12,13]$. This discrepancy could be due to the horizontal transfer of the 16SrRNA gene, as previously suggested [12]. Even using only SSU rDNA sequences, we could group MN7 to the 
391

392

393

394

395

396

397

398

399

400

401

402

403

404

405

406

407

408

409

410

411

412

413

414

415

416

417

418

419

420

421

422

423

424

$\mathrm{Hb} / \mathrm{Hm}$ clade (results not shown). The $\mathrm{Hb} / \mathrm{Hm}$ clade was established by concatenated sequences [12], but with $68 \%$ support values. In the last six years, this clade was populated with more strains and now contains, besides strains $\mathrm{Hb}$ and $\mathrm{Hm}, \mathrm{MX} 4 \mathrm{~A}$, Caborca and CH35 (see Figs 2 and S3). This enriched taxon sampling increased the support values to $94 \%$ when using DNA sequences of the genes SSU rDNA, gyrB, recA, gltX and dnaN $[11,12]$. The subspecies $P$. l. sonorensis proposed by Orozco et al. [11] includes strains Caborca and CH35. Our phylogenetic analysis, using the same concatenated gene sequences, shows, with good support values, that $\mathrm{Hb}$ and $\mathrm{Hm}$ are more closely related to each other than to MN7. Also, it is clear that these three taxa are not grouped within the sonorensis subspecies clade (Fig 2). The $\mathrm{Hb} / \mathrm{Hm}$ clade comprises the first Photorhabdus described and $\mathrm{Hb}$ is the type strain of Photorhabdus luminescens subsp. luminescens [1]. Hb was isolated in 1976 in Australia and Hm was isolated the same year in Tifton, Ga (USA), and although we know that Hb's symbiont was Heterorhabditis bacteriophora, the partner for Hm was undetermined [51]. Since then, both nematode strains have been lost (Patrick Tailliez, personal communication). Although MN7 also groups with $\mathrm{Hb} / \mathrm{Hm}$ when the alignment is done as previously suggested [13] (Fig 2c-d), the support for this clade is not as strong when using the ML approach.

The incapacity of $\mathrm{MN} 7$ of using $\mathrm{NH}_{4} \mathrm{Cl}$ as a nitrogen source suggests that it is auxotrophic for some nitrogen containing compounds. Other species of Photorhabdus require proline, tyrosine and serine as growth factors, as well as nicotinic acid and paraaminobenzoic acid [52]. Although tryptophanase and urease activities were not detected in the biochemical tests, the genes coding for both enzymes are present in the genome of MN7 (Alves et al., manuscript in preparation). The loss of some enzymatic activities is probably due to genome reduction, which is known to occur in pathogenic bacteria [53]. Another important aspect of MN7 biology is its resistance/sensitivity to antibiotics. Of all the antibiotics tested, $P$. luminescens MN7 was clearly resistant only to the betalactam ampicillin. Another study, performed with P. luminescens isolates [54], has shown that resistance to some antibiotics, as well as proteolytic activity, is positively correlated across these isolates,. The resistance of MN7 being restricted only to ampicillin but not to other beta-lactam antibiotics tested, suggests that the phenomenon is not due to a nonspecific detoxifying mechanism (like ABC transporters), but probably to an enzymatic activity that can only cleave the beta-lactam ring of ampicillin. 
425

426

427

428

429

430

431

432

433

434

435

436

437

438

439

440

441

442

443

444

445

446

447

448

449

450

presents crystalline inclusions in cells at stationary phase and also when in vitro cocultured with its partner H. baujardi LPP7 on nutrient agar (Fig 1). These crystalline inclusions are characteristic of Photorhabdus variant form I cells and necessary for the growth of the nematode partner [48]. Heterologously expressed crystalline inclusion polypeptides can shorten the life cycle and enhance the reproductive ability of freeliving nematodes [55]. Visual inspection of Galleria mellonella larvae infected with $H$. baujardi LPP7 clearly shows that the bioluminescence intensity is lower than that observed in H. bacteriophora HP88-infected G. mellonella (Figs 5a-d). This could be due to a lower number of bacteria inside the insect corpse. When the isolated bacteria from each of these strains are observed under the same culture conditions, we can clearly see that $P$. luminescens $\mathrm{MN} 7$ shows less bioluminescence than $P$. luminescens subsp. laumondii TT01 (Figs 5e-h). It is known that different species and strains of Photorhabdus show varying bioluminescence intensity [25]. It has been suggested [13] that light emission is a vestigial condition that was more intense in the original aquatic strains where the luxCDABE operon had evolved.

A preliminary analysis of the secondary metabolites produced by $P$. luminescens MN7 by HPLC-HRESI- identified an anthraquinone (1,3,8-trihydroxy-9,10anthraquinone), which could account for the dark-red color of the insect corpses (Fig 5a). Nevertheless, the amount of red pigment produced by MN7 in LB-agar is lower than in TT01 (Fig 3a). Anthraquinones produced by Photorhabdus temperata PtKandong are effective against the larvae of Culex pipiens pallens [7]. The stilbene (3,5dihydroxy-4-isopropyl-trans-stilbene) secreted by MN7 can inhibit the growth of the gram-positive bacterium Staphylococcus aureus, as was previously shown for other stilbenes [56]. Further studies of the genes coding for the enzymes involved in the biosynthesis of this stilbene can lead to the production of more effective antibiotics to be employed on this important human pathogen.

A secreted lipase activity is one of the criteria to define variant form I Photorhabdus isolates [57]. The bacteriological detection of lipase activity has shown that strain MN7 is capable of hydrolyzing Tween 80 better than Tween 20, whereas TT01 hydrolyzes Tween 20 better than Tween 80 (Fig 3a). Overall, MN7 shows a larger lipase activity zone around its colonies than TT01. These results strongly suggest that the isolate MN7 contains mainly variant form I cells.

Another aspect that is characteristic of variant form I Photorhabdus luminescens strains is the active production of insect toxins. To further support our decision of 
459 classifying MN7 within the Hb-Hm clade (Fig 2), we have established a bioassay for

460 oral toxins secreted in the growth medium. Previous results have shown that

461 Photorhabdus luminescens strains related to $\mathrm{W} 14, \mathrm{Hb}$ and $\mathrm{Hm}$ have the ability to

462 secrete toxins of the toxin complex with oral activity (Tc) [21]. The results of our assays

463 of Galleria mellonella growth rate clearly show that $P$. luminescens MN7 secretes a

464 heat-labile growth inhibitor in the medium, probably a toxin belonging to the Tc family

465 of toxins. The same assay, performed with bacteria isolated from Heterorhabditis

466 bacteriophora HP88, does not show any secreted toxin activity, as expected for

467 Photorhabdus luminescens subsp. laumondii HP88. Previous work on W14 Hb-Hm did

468 show the presence of a toxin in the spent medium that interfered with insect larval

469 growth [58]. Nevertheless, further studies excluded the possibility that secondary

470 metabolites were not involved in the toxic effect observed [58]. By heat inactivating the

471 spent medium of MN7 we were able to conclude that a protein factor (probably a Tc

472 toxin) is responsible for the effect we observed on the growth of larvae of Galleria

473 mellonella.

474 Other Photorhabdus species have been shown to secrete an important RTX

475 (repeat-in-toxin) metalo-protease, similar to serralysin belonging to the MA clan, sub-

476 family M10B [59]. MN7 secretes two proteases in the growth medium, one of them

477 corresponding to a $54 \mathrm{kDa}$ polypeptide, as described for the PrtA of $P$. luminescens

478 TT01 [60]. The other polypeptide, with a molecular mass of $38 \mathrm{kDa}$, probably

479 corresponds to PrtS, a poorly known protease with a broad spectrum of substrates [60].

480 These protease activities of $P$. luminescens MN7 show more intense bands than $P$.

481 luminescens TT01 (see Fig 3b). The presence of proteolytic activity bands of lower

482 molecular mass can only be detected in older cultures of TT01 but not in MN7. The

483 three secreted proteins of $P$. luminescens, tested in this work by different semi-

484 quantitative methods (lipase, Tc toxins and protease), show a higher activity in MN7

485 than in TT01, suggesting either a more efficient secretory pathway or higher level of

486 protein synthesis in $P$. luminescens MN7.

487 The results described here on P. luminescens MN7 will be important for a better

488 understanding of the relationship between this bacterium and its nematode partner,

489 Heterorhabditis baujardi LPP7.

490 
491

492

493

494

495

496

497

498

499

500

501

502

503

504

505

506

507

508

509

510

511

512

513

514

515

516

517

518

519

520

521

\section{Acknowledgements}

We would like to thank Drs S. Patricia Stock and Rousel A. Orozco (College of Agriculture and Life Sciences, University of Arizona, USA) for the sample of $P$. luminescens TT01 and Dr Claudia Dolinski, (Fluminense State University - UENF, RJ, Brazil) for the H. bacteriophora HP88 sample. We also thank Drs Mauro Cortez Veliz and Margareth L. Capurro Guimarães (Department of Parasitology, ICB, University of São Paulo - USP, São Paulo, Brazil). We thank Anderson Melo Gaia (Department of Fundamental Chemistry, IQ, USP, Brazil) for his invaluable help on the preliminary characterization of secondary metabolites of MN7. We also thank Beatriz N. M. de Miranda from the Center of Bionano Manufacturing at the Institute of Technological Research of São Paulo (IPT, São Paulo, Brazil) for the transmission electron microscopy analysis. We thank the expert technical assistance of Manoel Aparecido Peres.

\section{Author Contributions}

Conceptualization: CEW, AG

Data Curation: FLK, DPA, CR, MRCN, LMAM, CEW

Formal analysis: CEW, AG, JMPA

\section{Funding acquisition: CEW}

Investigation: FLK, DPA, CR, MRCN, LMAM, LFY, NCY, MJK, CEW

Methodology: FLK, DPA, CR, MRCN, LFY, NCY

Project administration: CEW, AG

Resources: CEW, MJK

Supervision: CEW

Visualization: CEW, AG

Writing - original draft: CEW, AG

Writing - review \& editing: CEW, AG, JMPA, FLK, MJK, LFY

\section{Data availability Statement}

Relevant data are available at the GenBank under the accessions: KY581573, KY581574, KY581575, KY581576, KY581577 and KY581578. 
bioRxiv preprint doi: https://doi org/10.1101/328377; this version posted May 22, 2018. The copyright holder for this preprint (which was not certified by peer review) is the author/funder, who has granted bioRxiv a license to display the preprint in perpetuity. It is made available under aCC-BY 4.0 International license.

\section{References}

1. Boemare N, Akhurst R. The Genera Photorhabdus and Xenorhabdus. In: Dworkin M, Falkow S, Rosenberg E, Schleifer K-H, Stackebrandt E, editors. The Prokaryotes.

6. New York: Springer New York; 2006. p. 451-494. https://doi.org/10.1007/0-38730746-X_16.

2. Nguyen $\mathrm{KB}$, Hunt DJ. Entomopathogenic nematodes: systematics, phylogeny and bacterial symbionts. Leiden-Boston: Brill; 2007. xv, 816 p.

3. Waterfield NR, Ciche T, Clarke D. Photorhabdus and a host of hosts. Annu Rev Microbiol. 2009;63:557-574.

https://doi.org/10.1146/annurev.micro.091208.073507. PMID: https://www.ncbi.nlm.nih.gov/pubmed/19575559.

4. Hussa EA, Goodrich-Blair H. It takes a village: ecological and fitness impacts of multipartite mutualism. Annu Rev Microbiol. 2013;67(1):161-178. https://doi.org/doi:10.1146/annurev-micro-092412-155723. PMID: https://www.ncbi.nlm.nih.gov/pubmed/23799814.

5. Ciche TA, Blackburn M, Carney JR, Ensign JC. Photobactin: a catechol siderophore produced by Photorhabdus luminescens, an entomopathogen mutually associated with Heterorhabditis bacteriophora NC1 nematodes. Appl Environ Microbiol. 2003;69(8):4706-4713. https://doi.org/10.1128/aem.69.8.4706-4713.2003. PMID: https://www.ncbi.nlm.nih.gov/pubmed/12902261.

6. Tobias NJ, Wolff H, Djahanschiri B, Grundmann F, Kronenwerth M, Shi YM, et al. Natural product diversity associated with the nematode symbionts Photorhabdus and Xenorhabdus. Nature microbiology. 2017;2(12):1676-1685.

https://doi.org/10.1038/s41564-017-0039-9. PMID: https://www.ncbi.nlm.nih.gov/pubmed/28993611.

7. Ahn JY, Lee JY, Yang EJ, Lee YJ, Koo KB, Song KS, et al. Mosquitocidal activity of anthraquinones isolated from symbiotic bacteria Photorhabdus of entomopathogenic nematode. J Asia-Pacif Entomol. 2013;16(3):317-320. https://doi.org/10.1016/j.aspen.2013.04.005.

8. Challinor VL, Bode HB. Bioactive natural products from novel microbial sources. Ann N Y Acad Sci. 2015;1354:82-97. https://doi.org/10.1111/nyas.12954. PMID: https://www.ncbi.nlm.nih.gov/pubmed/26509922.

9. Kontnik R, Crawford JM, Clardy J. Exploiting a global regulator for small molecule discovery in Photorhabdus luminescens. ACS Chem Biol. 2010;5(7):659-665. https://doi.org/10.1021/cb100117k. PMID: https://www.ncbi.nlm.nih.gov/pubmed/20524642.

10. Fischer-Le Saux M, Viallard V, Brunel B, Normand P, Boemare NE. Polyphasic classification of the genus Photorhabdus and proposal of new taxa: P. luminescens subsp. luminescens subsp. nov., P. luminescens subsp. akhurstii subsp. nov., $P$. luminescens subsp. laumondii subsp. nov., $P$. temperata sp. nov., P. temperata subsp. temperata subsp. nov. and P. asymbiotica sp. nov. Int J Syst Bacteriol. 1999;49 Pt 4:1645-1656. https://doi.org/10.1099/00207713-49-4-1645. PMID: https://www.ncbi.nlm.nih.gov/pubmed/10555346.

11. Orozco RA, Hill T, Stock SP. Characterization and phylogenetic relationships of Photorhabdus luminescens subsp. sonorensis (gamma-Proteobacteria: Enterobacteriaceae), the bacterial symbiont of the entomopathogenic nematode Heterorhabditis sonorensis (Nematoda: Heterorhabditidae). Curr Microbiol. 2013;66(1):30-39. https://doi.org/10.1007/s00284-012-0220-6. PMID: https://www.ncbi.nlm.nih.gov/pubmed/23053483. 
bioRxiv preprint doi: https://doi org/10.1101/328377; this version posted May 22, 2018. The copyright holder for this preprint (which was not certified by peer review) is the author/funder, who has granted bioRxiv a license to display the preprint in perpetuity. It is made available under aCC-BY 4.0 International license.

12. Tailliez P, Laroui C, Ginibre N, Paule A, Pages S, Boemare N. Phylogeny of Photorhabdus and Xenorhabdus based on universally conserved protein-coding sequences and implications for the taxonomy of these two genera. Proposal of new taxa: $X$. vietnamensis sp. nov., $P$. luminescens subsp. caribbeanensis subsp. nov., $P$. luminescens subsp. hainanensis subsp. nov., P. temperata subsp. khanii subsp. nov., $P$. temperata subsp. tasmaniensis subsp. nov., and the reclassification of $P$. luminescens subsp. thracensis as $P$. temperata subsp. thracensis comb. nov. Int J Syst Evol Microbiol. 2010;60(Pt 8):1921-1937. https://doi.org/10.1099/ijs.0.014308-0. PMID: https://www.ncbi.nlm.nih.gov/pubmed/19783607.

13. Peat SM, Ffrench-Constant RH, Waterfield NR, Marokhazi J, Fodor A, Adams BJ. A robust phylogenetic framework for the bacterial genus Photorhabdus and its use in studying the evolution and maintenance of bioluminescence: a case for $16 \mathrm{~S}$, gyrB, and $g \ln A$. Mol Phylogen Evol. 2010;57(2):728-740. https://doi.org/10.1016/j.ympev.2010.08.012. PMID: https://www.ncbi.nlm.nih.gov/pubmed/20732433.

14. Derzelle S, Duchaud E, Kunst F, Danchin A, Bertin P. Identification, characterization, and regulation of a cluster of genes involved in carbapenem biosynthesis in Photorhabdus luminescens. Appl Environ Microbiol. 2002;68(8):3780-3789. https://doi.org/10.1128/AEM.68.8.3780-3789.2002. PMID: https://www.ncbi.nlm.nih.gov/pubmed/12147472.

15. Clarke DJ. The genetic basis of the symbiosis between Photorhabdus and its invertebrate hosts. Adv Appl Microbiol. 2014;88:1-29. https://doi.org/10.1016/b978-0-12-800260-5.00001-2. PMID: https://www.ncbi.nlm.nih.gov/pubmed/24767424.

16. Boemare N, Givaudan A, Brehelin M, Laumond C. Symbiosis and pathogenicity of nematode-bacterium complexes. Symbiosis. 1997;22(1-2):21-45.

17. Somvanshi VS, Kaufmann-Daszczuk B, Kim K-s, Mallon S, Ciche TA. Photorhabdus phase variants express a novel fimbrial locus, $\mathrm{mad}$, essential for symbiosis. Mol Microbiol. 2010;77(4):1021-1038. https://doi.org/10.1111/j.13652958.2010.07270.x. PMID: https://www.ncbi.nlm.nih.gov/pubmed/20572934.

18. Rodou A, Ankrah DO, Stathopoulos C. Toxins and Secretion Systems of Photorhabdus luminescens. Toxins. 2010;2(6):1250-1264. https://doi.org/10.3390/toxins2061250. PMID: https://www.ncbi.nlm.nih.gov/pubmed/22069636.

19. Daborn PJ, Waterfield N, Silva CP, Au CPY, Sharma S, Ffrench-Constant RH. A single Photorhabdus gene, makes caterpillars floppy ( $m c f)$, allows Escherichia coli to persist within and kill insects. Proc Natl Acad Sci USA. 2002;99(16):1074210747. https://doi.org/10.1073/pnas.102068099. PMID: https://www.ncbi.nlm.nih.gov/pubmed/12136122.

20. Aktories K, Schmidt G, Lang AE. Photorhabdus luminescens Toxins TccC 3 and TccC5: Insecticidal ADP-Ribosyltransferases that Modify Threonine and Glutamine. Curr Top Microbiol Immunol. 2015;384:53-67. https://doi.org/10.1007/82 2014 382. PMID: https://www.ncbi.nlm.nih.gov/pubmed/24908144.

21. Yang G, Hernandez-Rodriguez CS, Beeton ML, Wilkinson P, Ffrench-Constant RH, Waterfield NR. Pdl1 Is a Putative Lipase that Enhances Photorhabdus Toxin Complex Secretion. PLoS Pathog. 2012;8(5). https://doi.org/10.1371/journal.ppat.1002692. PMID: https://www.ncbi.nlm.nih.gov/pubmed/22615559. 
bioRxiv preprint doi: https://doi org/10.1101/328377; this version posted May 22, 2018. The copyright holder for this preprint (which was not certified by peer review) is the author/funder, who has granted bioRxiv a license to display the preprint in perpetuity. It is made available under aCC-BY 4.0 International license.

22. Felföldi G. The role of a serralysin PrtA system in the infection mechanism of an entomopathogen, Photorhabdus [PhD]. Budapest, Hungary: Eötvös Loránd University; 2010. Available from: http://teo.elte.hu/minosites/tezis2010 angol/g felfoldi.pdf.

23. Felföldi G, Marokhazi J, Kepiro M, Venekei I. Identification of Natural Target Proteins Indicates Functions of a Serralysin-Type Metalloprotease, PrtA, in AntiImmune Mechanisms. Appl Environ Microbiol. 2009;75(10):3120-3126. https://doi.org/10.1128/aem.02271-08. PMID: https://www.ncbi.nlm.nih.gov/pubmed/WOS:000265908500016.

24. Boemare NE, Akhurst RJ, Mourant RG. DNA relatedness between Xenorhabdus spp. (Enterobacteriaceae), symbiotic bacteria of entomopatogenic nematodes, and a proposal to transfer Xenorhabdus luminescens to a new genus, Photorhabdus gen. nov. Int J Syst Bacteriol. 1993;43(2):249-255. https://doi.org/10.1099/0020771343-2-249.

25. Koppenhöfer HS. Bacterial symbionts of Steinernema and Heterorhabditis. In: Nguyen KB, Hunt DJ, editors. Entomopathogenic nematodes: systematics, phylogeny and bacterial symbionts. Nematology Monographs and Perspectives. 1st ed. Leiden-Boston: Brill; 2007. p. 735-808.

26. Hyrsl P, Ciz M, Lojek A. Comparison of the bioluminescence of Photorhabdus species and subspecies type strains. Folia Microbiol. 2004;49(5):539-542. https://doi.org/10.1007/BF02931530. PMID: https://www.ncbi.nlm.nih.gov/pubmed/15702542.

27. Brameyer S, Heermann R. Specificity of Signal-Binding via Non-AHL LuxR-Type Receptors. PLoS One. 2015;10(4):e0124093. https://doi.org/10.1371/journal.pone.0124093. PMID: https://www.ncbi.nlm.nih.gov/pubmed/25923884.

28. Dolinski C, Kamitani FL, Machado IR, Winter CE. Molecular and morphological characterization of heterorhabditid entomopathogenic nematodes from the tropical rainforest in Brazil. Mem Inst Oswaldo Cruz. 2008;103(2):150-159. https://doi.org/10.1590/S0074-02762008000200005. PMID: https://www.ncbi.nlm.nih.gov/pubmed/18425267.

29. Kaya HK, Stock SP. Techniques in insect nematology. In: Lacey LA, editor. Manual of Tecniques in Insect Pathology. Biological Techniques. San Diego: Academic Press; 1997. p. 281-324.

30. Bertani G. Studies on Lysogenesis. I. The mode of phage liberation by lysogenic Escherichia coli. J Bacteriol. 1951;62(3):293-300. PMID: https://www.ncbi.nlm.nih.gov/pubmed/14888646.

31. Giandomenico AR, Cerniglia GE, Biaglow JE, Stevens CW, Koch CJ. The importance of sodium pyruvate in assessing damage produced by hydrogen peroxide. Free Radical Biol Med. 1997;23(3):426-434. https://doi.org/10.1016/S0891-5849(97)00113-5. PMID: https://www.ncbi.nlm.nih.gov/pubmed/9214579.

32. Blackburn D, Burk TJ, Adams BJ. Virulence modulation in Photorhabdus spp. Nematology. 2016;18(6):711-717. https://doi.org/10.1163/15685411-00002986.

33. Sanger F, Nicklen S, Coulson AR. DNA sequencing with chain-terminating inhibitors. Proc Natl Acad Sci USA. 1977;74(12):5463-5467. PMID: https://www.ncbi.nlm.nih.gov/pubmed/271968.

34. Ronaghi M, Karamohamed S, Pettersson B, Uhlen M, Nyren P. Real-time DNA sequencing using detection of pyrophosphate release. Anal Biochem. 
bioRxiv preprint doi: https://doi org/10.1101/328377; this version posted May 22, 2018. The copyright holder for this preprint (which was not certified by peer review) is the author/funder, who has granted bioRxiv a license to display the preprint in perpetuity. It is made available under aCC-BY 4.0 International license.

1996;242(1):84-89. https://doi.org/10.1006/abio.1996.0432. PMID:

https://www.ncbi.nlm.nih.gov/pubmed/8923969.

35. Larkin MA, Blackshields G, Brown NP, Chenna R, McGettigan PA, McWilliam H, et al. Clustal W and Clustal X version 2.0. Bioinformatics. 2007;23(21):2947-2948. https://doi.org/10.1093/bioinformatics/btm404. PMID: https://www.ncbi.nlm.nih.gov/pubmed/17846036.

36. Waterhouse AM, Procter JB, Martin DM, Clamp M, Barton GJ. Jalview Version 2 a multiple sequence alignment editor and analysis workbench. Bioinformatics. 2009;25(9):1189-1191. https://doi.org/10.1093/bioinformatics/btp033. PMID: https://www.ncbi.nlm.nih.gov/pubmed/19151095.

37. Schwarz G. Estimating the dimension of a model. Ann Statist. 1978;6:461-464.

38. Darriba D, Taboada GL, Doallo R, Posada D. jModelTest 2: more models, new heuristics and parallel computing. Nat Methods. 2012;9(8):772. https://doi.org/10.1038/nmeth.2109. PMID: https://www.ncbi.nlm.nih.gov/pubmed/22847109.

39. Kück P, Meusemann K. FASconCAT: Convenient handling of data matrices. Mol Phylogen Evol. 2010;56(3):1115-1118. https://doi.org/10.1016/j.ympev.2010.04.024. PMID: https://www.ncbi.nlm.nih.gov/pubmed/20416383.

40. Ronquist F, Huelsenbeck JP. MrBayes 3: Bayesian phylogenetic inference under mixed models. Bioinformatics. 2003;19(12):1572-1574.

https://doi.org/10.1093/bioinformatics/btg180. PMID: https://www.ncbi.nlm.nih.gov/pubmed/12912839.

41. Stamatakis A. RAxML-VI-HPC: maximum likelihood-based phylogenetic analyses with thousands of taxa and mixed models. Bioinformatics. 2006;22(21):2688-2690. https://doi.org/10.1093/bioinformatics/btl446. PMID: https://www.ncbi.nlm.nih.gov/pubmed/16928733.

42. Toledo MRF, Fontes CF, Trabulsi LR. MILi um meio para a realização dos testes de motilidade, indol e lisina descarboxilase. Rev Microbiol. 1982;13:230-235.

43. Toledo MRF, Fontes CF, Trabulsi LR. EPM-modificação do meio de Rugai e Araújo para a realização simultânea dos testes de produção de gás a partir de glicose, $\mathrm{H}_{2} \mathrm{~S}$, urease e triptofano desaminase. Rev Microbiol. 1982;13:309-315.

44. Schagger H, von Jagow G. Tricine-sodium dodecyl sulfate-polyacrylamide gel electrophoresis for the separation of proteins in the range from 1 to $100 \mathrm{kDa}$. Anal Biochem. 1987;166(2):368-379. https://doi.org/10.1016/0003-2697(87)90587-2. PMID: https://www.ncbi.nlm.nih.gov/pubmed/2449095.

45. Sierra G. A simple method for the detection of lipolytic activity of micro-organisms and some observations on the influence of the contact between cells and fatty substrates. Antonie Van Leeuwenhoek. 1957;23(1):15-22. https://doi.org/10.1007/BF02545855. PMID: https://www.ncbi.nlm.nih.gov/pubmed/13425509.

46. Burghardt RC, Droleskey R. Transmission electron microscopy. Current protocols in microbiology. Chapter 2. 2008/09/05 ed2006. p. Unit 2B.1. https://doi.org/10.1002/9780471729259.mc02b01s0. PMID: https://www.ncbi.nlm.nih.gov/pubmed/18770588.

47. Ramarao N, Nielsen-Leroux C, Lereclus D. The insect Galleria mellonella as a powerful infection model to investigate bacterial pathogenesis. JoVE. 2012;(70):e4392. https://doi.org/10.3791/4392. PMID: https://www.ncbi.nlm.nih.gov/pubmed/23271509. 
bioRxiv preprint doi: https://doi org/10.1101/328377; this version posted May 22, 2018. The copyright holder for this preprint (which was not certified by peer review) is the author/funder, who has granted bioRxiv a license to display the preprint in perpetuity. It is made available under aCC-BY 4.0 International license.

48. You J, Liang S, Cao L, Liu X, Han R. Nutritive significance of crystalline inclusion proteins of Photorhabdus luminescens in Steinernema nematodes. FEMS Microbiol Ecol. 2006;55(2):178-185. https://doi.org/10.1111/j.1574-6941.2005.00015.x. PMID: https://www.ncbi.nlm.nih.gov/pubmed/16420626.

49. Kumar SN, Nambisan B, Sundaresan A, Mohandas C, Anto RJ. Isolation and identification of antimicrobial secondary metabolites from Bacillus cereus associated with a rhabditid entomopathogenic nematode. Annals of Microbiology. 2014;64(1):209-218. https://doi.org/10.1007/s13213-013-0653-6.

50. Stock SP, Rivera-Orduno B, Flores-Lara Y. Heterorhabditis sonorensis n. sp. (Nematoda: Heterorhabditidae), a natural pathogen of the seasonal cicada Diceroprocta ornea (Walker) (Homoptera: Cicadidae) in the Sonoran desert. J Invertebr Pathol. 2009;100(3):175-184. https://doi.org/10.1016/j.jip.2008.11.011. PMID: https://www.ncbi.nlm.nih.gov/pubmed/19114047.

51. Thomas GM, Poinar GO. Xenorhabdus gen. nov., a genus of entomopathogenic, nematophilic bacteria of the family Enterobacteriaceae. Int J Syst Bacteriol. 1979;29(4):352-360. https://doi.org/10.1099/00207713-29-4-352.

52. Grimont PAD, Steigerwalt AG, Boemare N, Hickmanbrenner FW, Deval C, Grimont F, et al. Deoxyribonucleic-acid relatedness and phenotypic study of the genus Xenorhabdus. Int J Syst Bacteriol. 1984;34(4):378-388. https://doi.org/10.1099/00207713-34-4-378.

53. Georgiades K, Raoult D. Defining pathogenic bacterial species in the genomic era. Front Microbiol. 2011;1(1):151. https://doi.org/10.3389/fmicb.2010.00151. PMID: https://www.ncbi.nlm.nih.gov/pubmed/21687765.

54. Hatab MA, Stuart RJ, Gaugler R. Antibiotic resistance and protease production by Photorhabdus luminescens and Xenorhabdus poinarii bacteria symbiotic with entomopathogenic nematodes: variation among species and strains. Soil Biol Biochem. 1998;30(14):1955-1961. https://doi.org/10.1016/S0038-0717(98)00067$\underline{4}$.

55. Juan Y, Jian-lin H, Li C, Ri-chou H. Development of a Free-living nematode Panagrellus redivivus in Saccharomyces cerevisiae with cip genes. Chin J Biotechnol. 2011;31(04):44-52.

56. Lee K, Lee JH, Ryu SY, Cho MH, Lee J. Stilbenes reduce Staphylococcus aureus hemolysis, biofilm formation, and virulence. Foodborne Pathog Dis. 2014;11(9):710-717. https://doi.org/10.1089/fpd.2014.1758. PMID: https://www.ncbi.nlm.nih.gov/pubmed/25007234.

57. Wang H, Dowds BC. Phase variation in Xenorhabdus luminescens: cloning and sequencing of the lipase gene and analysis of its expression in primary and secondary phases of the bacterium. J Bacteriol. 1993;175(6):1665-1673. https://doi.org/10.1128/jb.175.6.1665-1673.1993 PMID: https://www.ncbi.nlm.nih.gov/pubmed/8449874.

58. Waterfield N, Dowling A, Sharma S, Daborn PJ, Potter U, Ffrench-Constant RH. Oral toxicity of Photorhabdus luminescens W14 toxin complexes in Escherichia coli. Appl Environ Microbiol. 2001;67(11):5017-5024. https://doi.org/10.1128/aem.67.11.5017-5024.2001. PMID: https://www.ncbi.nlm.nih.gov/pubmed/11679320.

59. Rawlings ND, Barrett AJ, Finn R. Twenty years of the MEROPS database of proteolytic enzymes, their substrates and inhibitors. Nucleic Acids Res. 2016;44(D1):D343-350. https://doi.org/10.1093/nar/gkv1118. PMID: https://www.ncbi.nlm.nih.gov/pubmed/26527717. 
60. Cabral CM, Cherqui A, Pereira A, Simoes N. Purification and characterization of two distinct metalloproteases secreted by the entomopathogenic bacterium Photorhabdus sp. strain Az29. Appl Environ Microbiol. 2004;70(7):3831-3838. https://doi.org/10.1128/aem.70.7.3831-3838.2004. PMID: https://www.ncbi.nlm.nih.gov/pubmed/15240252.

61. Gutell RR, Weiser B, Woese CR, Noller HF. Comparative anatomy of 16-S-like ribosomal RNA. Prog Nucleic Acid Res Mol Biol. 1985;32:155-216. https://doi.org/10.1016/S0079-6603(08)60348-7. PMID: https://www.ncbi.nlm.nih.gov/pubmed/3911275.

62. Petrov AS, Bernier CR, Gulen B, Waterbury CC, Hershkovits E, Hsiao C, et al. Secondary structures of rRNAs from all three domains of life. PLoS One. 2014;9(2):e88222. https://doi.org/10.1371/journal.pone.0088222. PMID: https://www.ncbi.nlm.nih.gov/pubmed/24505437.

\section{Supporting information}

S1 Table. Oligonucleotides used for sequencing SSU rRNA gene fragments from $P$. luminescens strain MN7. *Oligonucleotide prefix names BSF and BSR refer to forward and reverse orientations, respectively.

S2 Table. Photorhabdus spp. DNA sequences used for phylogenetic analysis. According to Orozco et al. [11]

S3 Table. Photorhabdus spp. DNA sequences used for phylogenetic analysis. According to Peat et al. [13]

S4 Fig Initial larvae weight of Galleria mellonella used in the oral toxin assays shown in Fig 6. Each of the five experimental groups are shown separately. Larvae used in the three biological replicates are plotted in the graph.

S5 File. Supplemental Materials and methods.

S6 Fig Predicted secondary structure of the SSU rRNA of $\boldsymbol{P}$. luminescens strain MN7. This putative structure was constructed by superimposing the MN7 SSU rRNA sequence over the 2D model of E. coli SSU rRNA [61, 62]. The three main stems of the 16S rRNA are depicted in Roman numerals. Tertiary interactions with strong comparative data are connected by solid lines. The stems and loops used to construct the alignments shown in Fig 2 are highlighted in blue background. Variable loops in $\gamma$ proteobacteria are labeled with gray-filled circles.

S7 Fig Multiple sequences alignment of selected regions of the SSU rRNA gene sequence of different Photorhabdus species and some other enterobacteria. The alignment shows regions containing loops (labeled in red) and the surrounding stem regions (labeled in blue). Brackets above the alignment correspond to the regions depicted in S6 Fig. Numbering of the regions follows the E. coli SSU rRNA secondary structure model [62].

S8 Fig Maximum likelihood phylogenetic tree of Photorhabdus spp. concatenated sequences of SSU rDNA, gyrB, recA, gltX and $\boldsymbol{d n} \boldsymbol{A} N$ (S2 Table). The tree was 
constructed using RAxML. Partitioned bootstrap support values were obtained from 1,000 pseudoreplicates and are shown over each node. Outgroups used were: Yersinia pestis CO92, Salmonella enterica CT18 and Escherichia coli IAI39. The scale bars show changes per site.

\section{S9 Fig Maximum likelihood phylogenetic tree of Photorhabdus spp. concatenated} sequences of SSU rDNA genes, $g \ln A, \operatorname{gyrB}$ (S3 Table). The tree was constructed using RAxML. Partitioned bootstrap support values were obtained from 5,000 pseudoreplicates and are shown over each node. Outgroups used in all analyses were: Yersinia pestis CO92, Salmonella enterica CT18 and Escherichia coli IAI39. The scale bars show changes per site.

S10 Fig Bayesian phylogenetic tree of Photorhabdus spp. concatenated sequences of SSU rDNA, gyrB, recA, gltX and dnaN (S2 Table). The tree was constructed using MrBayes. Posterior probability values were obtained from 1,000,000 generations and are shown over each node. Outgroups used in all analyses were: Yersinia pestis CO92, Salmonella enterica CT18 and Escherichia coli IAI39. The scale bars show changes per site.

S11 Fig Bayesian phylogenetic tree of Photorhabdus spp. concatenated sequences of $g \ln A, g y r$ B, SSU rDNA, genes from several Photorhabdus species (S3 Table). The tree was constructed using MrBayes. Posterior probability values were obtained from 1,500,000 generations and are shown over each node. Outgroups used in all analyses were: Yersinia pestis CO92, Salmonella enterica CT18 and Escherichia coli IAI39. The scale bars show changes per site.

S12 Table. Exact mass and putative formulae of the compounds assigned to the peaks detected by HPLC and analyzed by high resolution mass spectrometry. *Peaks are numbered according to Fig 7.

S13 Fig Mass spectra of peaks 4 (a) and 5 (b) found in the HPLC profile of secondary metabolites produced by $P$. luminescens MN7 (see Fig 7). Material obtained from the HPLC profile was submitted to ESI-MS and the $\mathrm{m} / \mathrm{z}$ of each quasimolecular ion is depicted in the profile, with retention times shown on the left and putative structures on the right.

\section{S14 Fig Analytical TLC of the anthraquinone and stilbene fractions purified by} preparative TLC. Purified fractions were separated by analytical TLC and developed as described in Supplementary Material and Methods (S5 File), with ethyl acetate:hexane $(1: 1 ; \mathrm{v} / \mathrm{v})$ as the mobile phase. (a) and (c) anthraquinone sample; (b) and (d) stilbene sample. Samples were observed under visible light (a and b) and under UV light (c and d). 


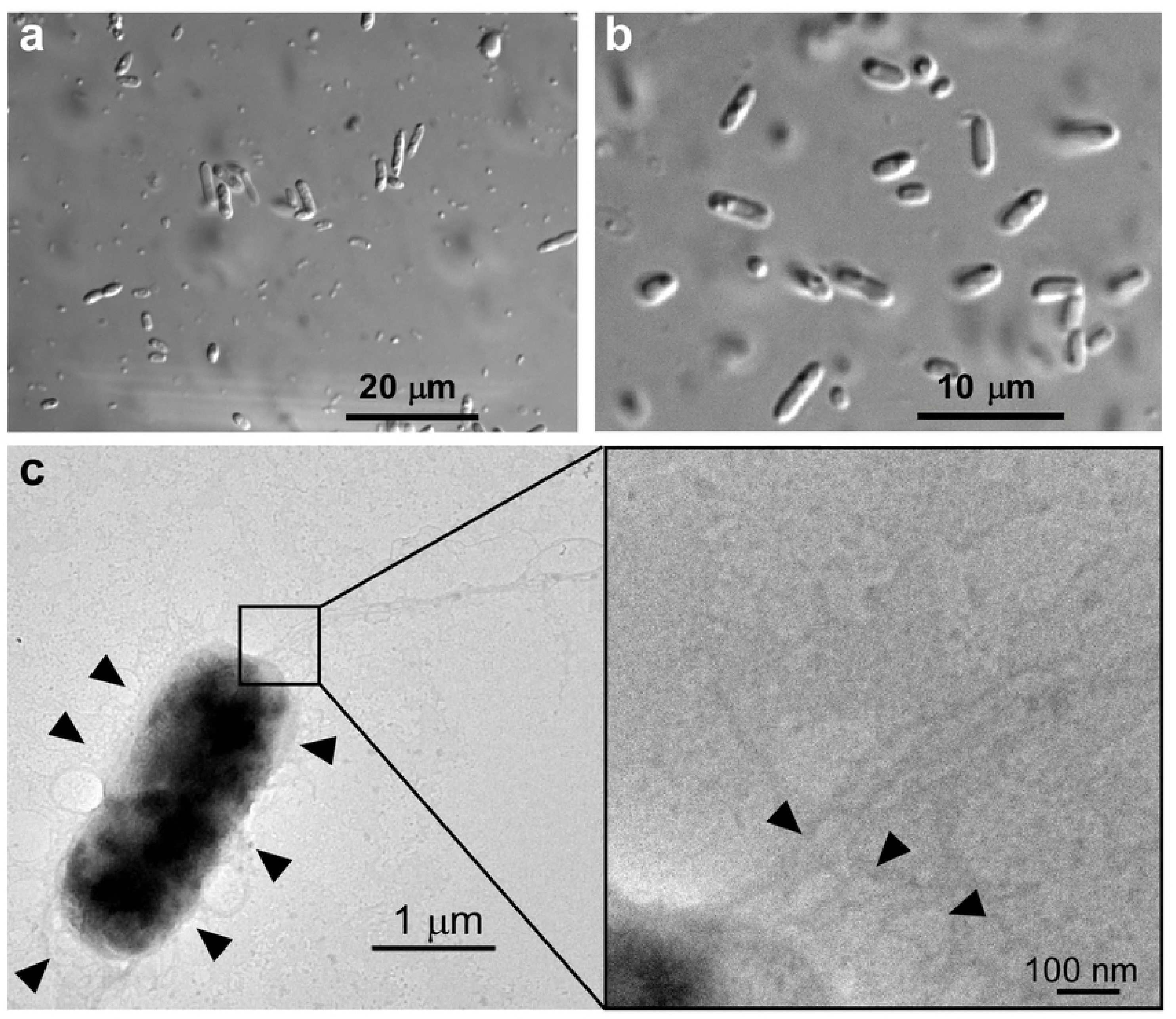


a
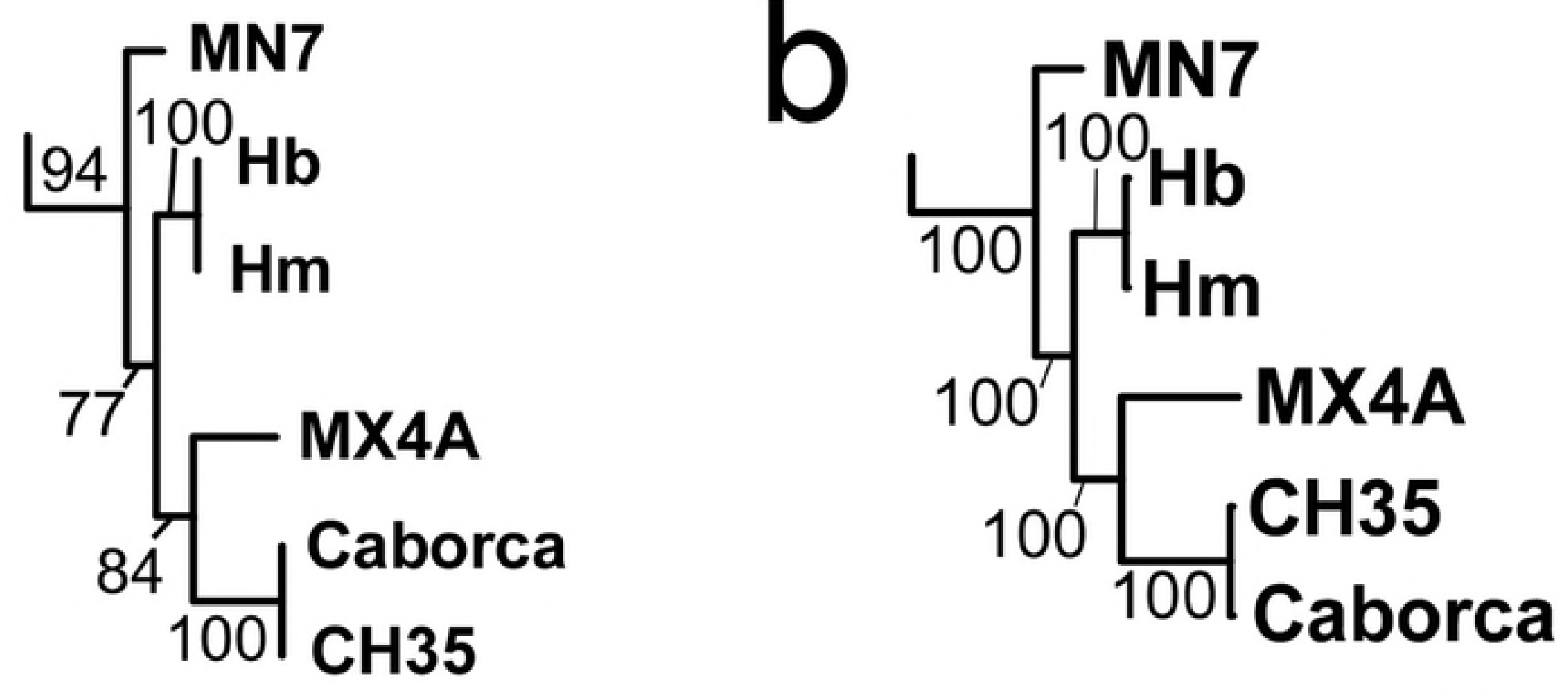

$\overline{0.02}$
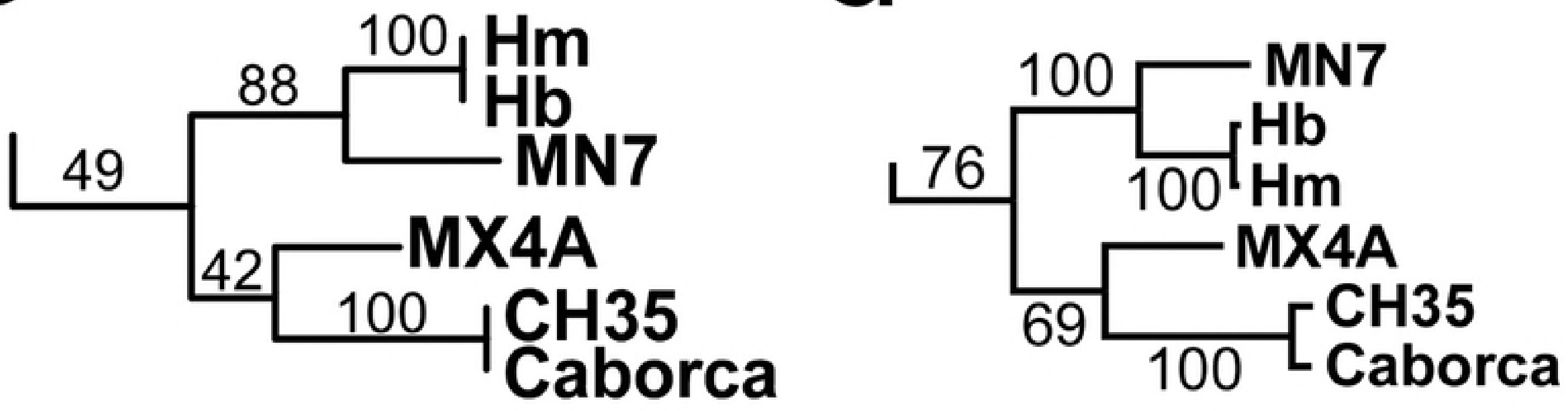


\section{MN7}

TT01
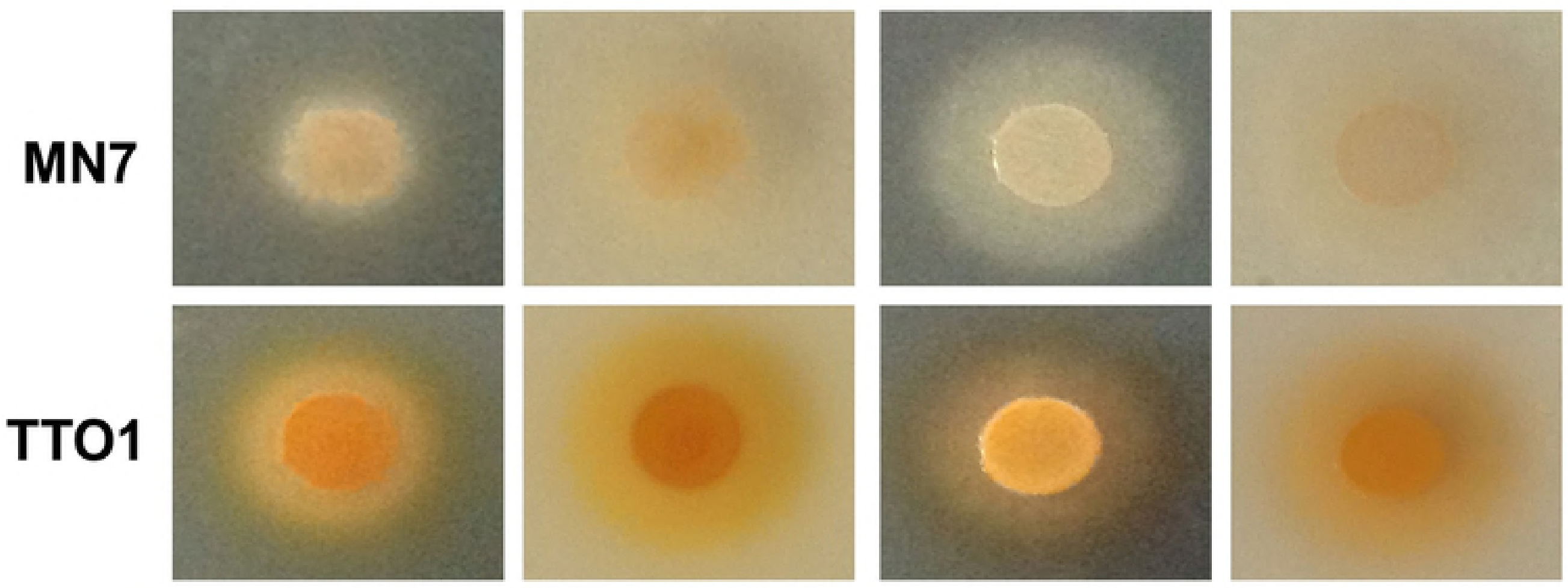

b

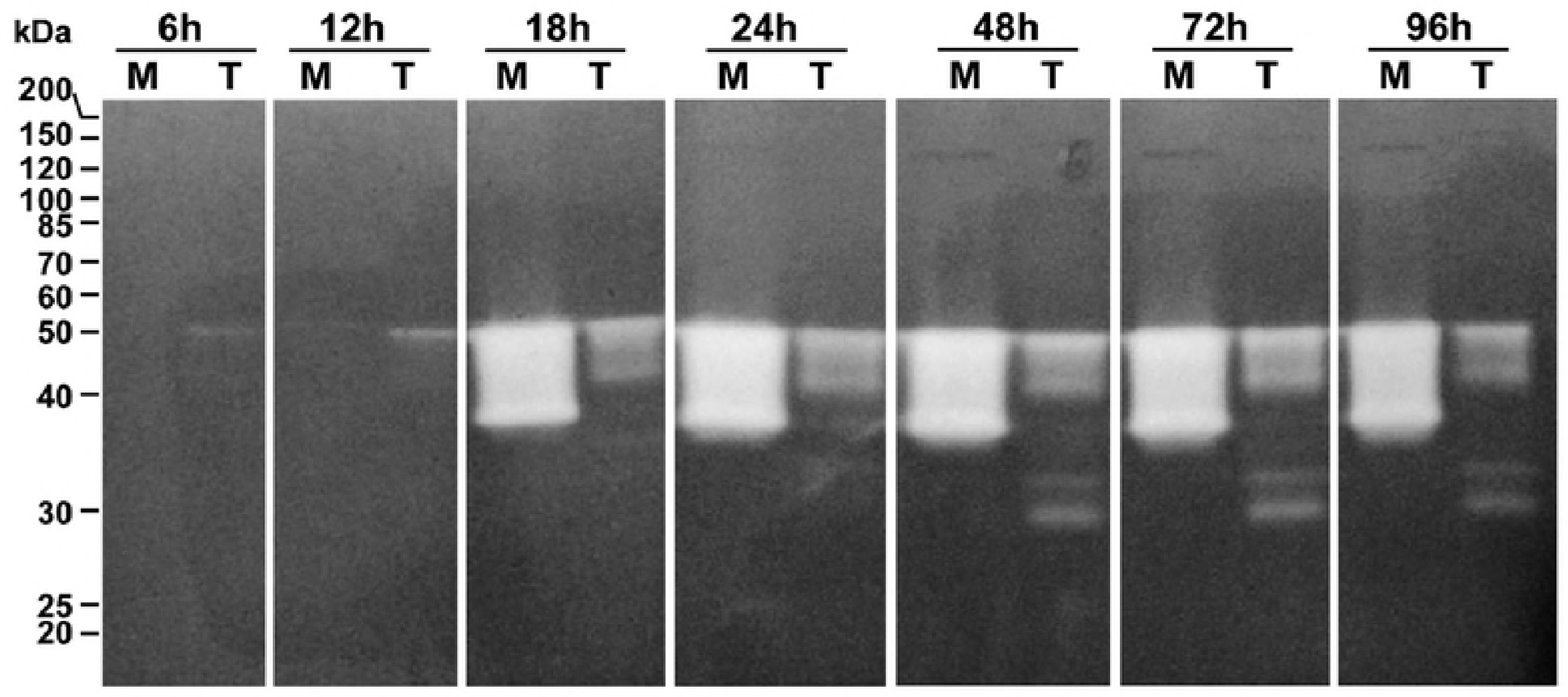




\section{ciprofloxacin}

amoxicillin

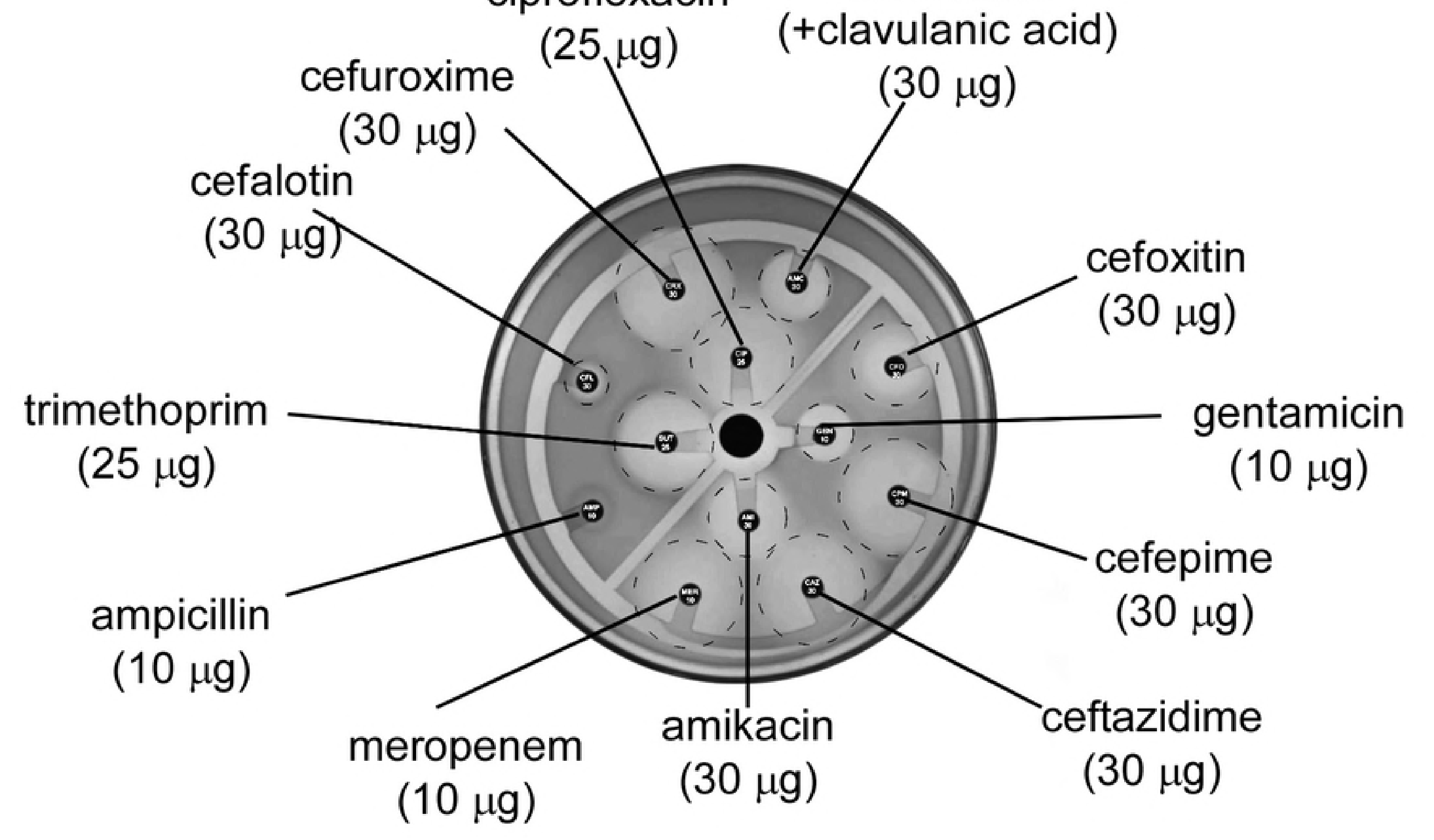




\section{a}
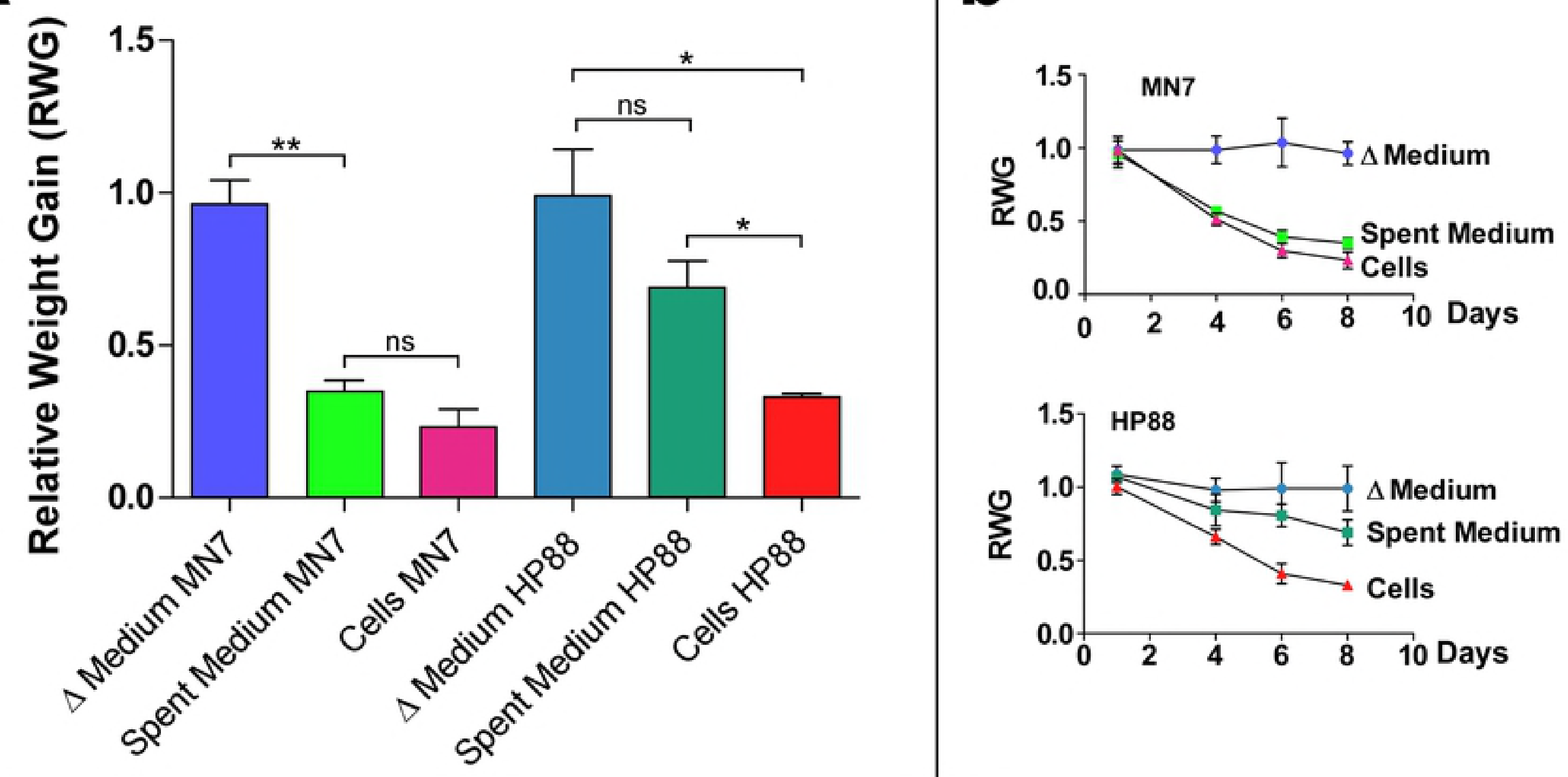


\section{a}

Intens.

[mAU] 40
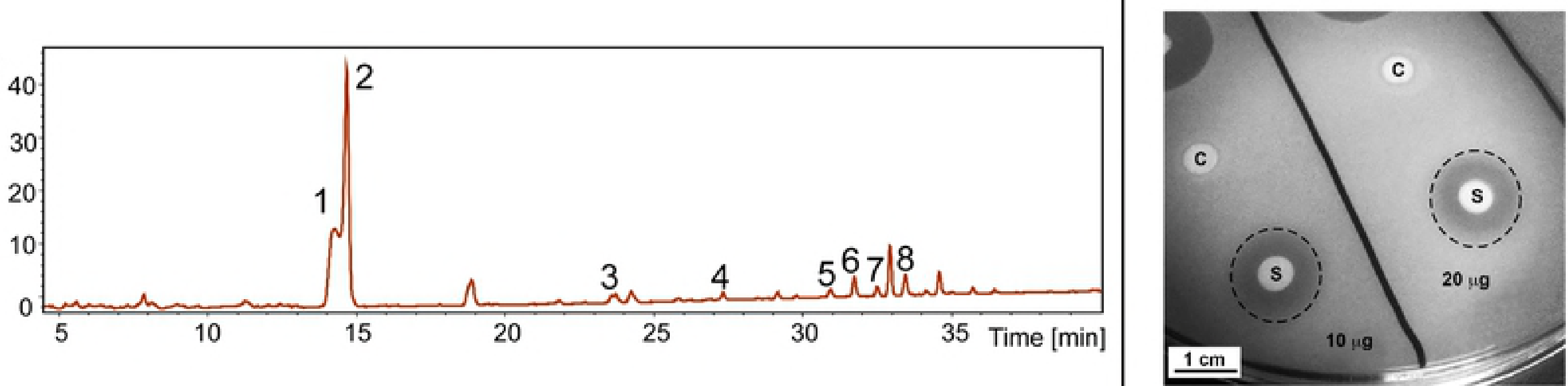